University of Nebraska - Lincoln

DigitalCommons@University of Nebraska - Lincoln

Nebraska Cooperative Fish \& Wildlife Research Nebraska Cooperative Fish \& Wildlife Research Unit -- Staff Publications

2002

\title{
Cross-scale Structure and Scale Breaks in Ecosystems and Other Complex Systems
}

Craig R. Allen

University of Nebraska-Lincoln, callen3@unl.edu

C. S. Holling

University of Florida

Follow this and additional works at: https://digitalcommons.unl.edu/ncfwrustaff

Part of the Other Environmental Sciences Commons

Allen, Craig R. and Holling, C. S., "Cross-scale Structure and Scale Breaks in Ecosystems and Other Complex Systems" (2002). Nebraska Cooperative Fish \& Wildlife Research Unit -- Staff Publications. 5. https://digitalcommons.unl.edu/ncfwrustaff/5

This Article is brought to you for free and open access by the Nebraska Cooperative Fish \& Wildlife Research Unit at DigitalCommons@University of Nebraska - Lincoln. It has been accepted for inclusion in Nebraska Cooperative Fish \& Wildlife Research Unit -- Staff Publications by an authorized administrator of DigitalCommons@University of Nebraska - Lincoln. 


\title{
Cross-scale Structure and Scale Breaks in Ecosystems and Other Complex Systems
}

\author{
Craig R. Allen ${ }^{1 *}$ and C. S. Holling ${ }^{2}$
}

\begin{abstract}
${ }^{1}$ US Geological Survey, Biological Resources Division, South Carolina Cooperative Fish and Wildlife Research Unit, Clemson University, Clemson, South Carolina, 29634, USA; and ${ }^{2}$ Department of Zoology, 110 Bartram, University of Florida, Gainesville, Florida, 32611, USA
\end{abstract}

The five articles in this special feature extend the discovery of regular patterns of deviation from scaling laws and from continuous distributions of attributes in ecosystems and other complex systems. These patterns suggest that these systems organize over discrete ranges of scale and that organization abruptly shifts with changes in scale. If this is so, scaling laws (for example, see West 1997, 1999; Zipf 1949) serve only as the baseline from which to measure those departures, and those departures indicate "scale breaks" (transitions) between scales of structure in complex systems. Patterns in the deviations from a scaling-law baseline may provide hints of the processes that cause the emergence of the scaling relationships themselves. At minimum, the investigation of departures from scaling laws gives us a clue into the nature of structure and process in ecological systems.

Ecosystems may be structured by relatively few key processes, each operating at specific temporal and spatial scales (Carpenter and Leavitt 1991; Levin 1992). The distinct temporal frequencies and spatial scale characterizing these processes creates landscape structures with scale-specific pattern (Burrough 1981; O'Neill and others 1991; Milne and others 1992). This may in turn entrain attributes of animals residing on the landscape (Holling 1992) because different-sized animals living upon the same landscape perceive their environment at different scales (Milne and others 1989; Holling 1992; Peterson and others 1998) (Figure 1).

Received 25 January 2002; accepted 28 January 2002.

*Corresponding author; e-mail: allencr@clemson.edu
Holling (1992) suggested that this entrainment reflects adaptations to the discontinuous pattern of resource distribution acting through animal community assembly and evolution, both by sorting species and by providing a specific set of evolutionary opportunities and constraints. On the animal community level, this should be expressed by a discontinuous distribution of species body masses (Holling 1992). Within a system, aggregations of species body masses are separated by discrete breaks (or discontinuities) separating different ranges of scale. Animals within a particular body mass aggregation perceive and exploit the environment at the same range of scale (Peterson and others 1998) (Figure 2).

Holling's proposition that ecosystem structure entrains attributes of animals-such as body mass distributions (the textural discontinuity hypothesis) - was received with some skepticism, but also with interest. It is now generally accepted that many attributes of ecosystems are discontinuously distributed, but mechanisms other than entrainment by ecological structure (Brown 1995) have been proposed. However, most of the disagreements with Holling's proposition have been technical, focusing on the methods used to detect discontinuities (Manly 1996; Siemann and Brown 1999).

New evidence for a link between landscape structure at different scales and body mass distributions has provided support for the textural discontinuity hypothesis. Discontinuous body mass patterns have been documented in many systems (see for example, Holling 1992; Restrepo and others 1997; Lambert and Holling 1998; Allen and others 1999; Raf- 


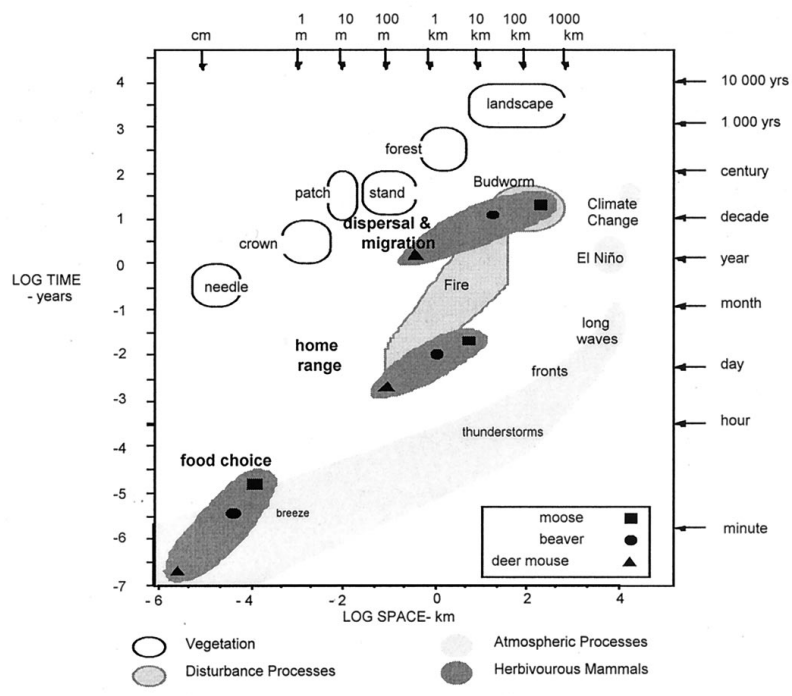

Figure 1. Time and space scales of the boreal forest and their relationship to some of the processes that structure the forest. These processes include insect outbreaks, fire, atmospheric processes, and the rapid carbon dioxide increase in modern times. Scales at which deer mouse, beaver, and moose choose food items, occupy a home range, and disperse to locate suitable home ranges vary with their body size. Adapted from Peterson and others (1998).

faelli and others 2000; Havlicek and Carpenter 2001). The analyses of Raffaelli and others (2000) and Havlicek and Carpenter (2001), further suggest that discontinuous patterns within animal body mass distributions are conservative, robust to perturbations and species turnover. The association of scale breaks with attributes of species independent of the determination of body mass structure, invasiveness, and decline (Allen and others 1999) has provided additional support that the patterns identified in body mass distributions are in fact real.

The analysis of landscape patterns has demonstrated that changes in spatial pattern across different ranges of scales are described by different scaling relationships (Krummel and others 1987), and the analysis of the relationship between species richness and spatial scale has established the existence of different scaling relationships at different scales (Crawley and Harral 2001). In between scales, there are sharp breaks between these scaling regimes (Krummel and others 1987; Crawley and Harral 2001).

For obvious reasons, a direct experimental link between body mass aggregations and landscape pattern across scales remains elusive, but a relationship between body mass and vegetation structure has been demonstrated (Morse and others 1988; Shor-

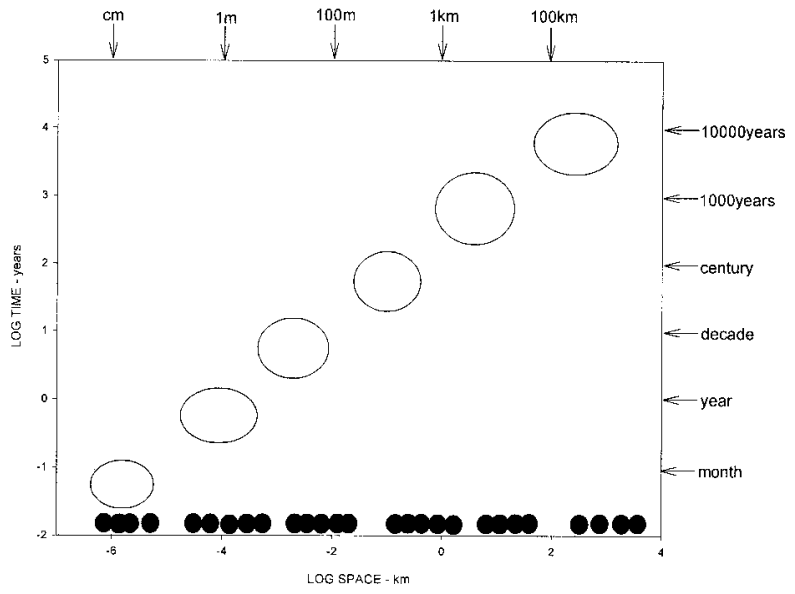

Figure 2. Animal body mass patterns reflect the scalespecific domains of key structuring processes. Space-time domains of a hypothetical system are shown as open circles; body mass distribution of a hypothetical animal community entrained by these processes is indicated by black circles on an ascending body mass axis (not shown). Patterns in the animal body mass distribution reflect scales of structure available in the system.

rocks 1991). Raffaelli and others (2000) were able to conduct manipulations of marine sediment invertebrate assemblages, and they established that perturbations affected densities and abundance of taxa but that patterns in the size spectra were conserved. They concluded that the size spectra were probably constrained by habitat structure.

In this special feature of Ecosystems, we further explore the causes, commonality, and consequences of discontinuous structure in complex systems, with a focus on ecosystems. This feature consists of five papers. The first (Holling and Allen 2002) outlines the difficulties, and suggests a remedy, in analyzing seemingly intractable ecological data where causes are multiple, scales of influence many, and experimental manipulation impossible. Statistics, especially frequentist statistics, fail to detect pattern in data such as body mass or city-size distributions; and the manipulation of entire ecosystems at multiple scales with replication is more than a challenge. Thus, a more fluid approach is needed to determine the most likely mechanisms underlying discontinuities and to make comparisons of patterns among different systems. Holling and Allen describe an approach called "adaptive inference," which sorts and sifts among multiple, overlapping, and not entirely separable causes of structure in ecosystems.

Critical for support of the textural discontinuity hypothesis is the identification of the mechanisms 
that generate such discontinuities. Peterson (2002) uses spatial modeling of fire to explore how contagious disturbances may structure ecosystems across a broad range of scales. He demonstrates how the ecological "memory" of past fires influences the persistence of spatial structure at different scales. He shows that spatial pattern can be produced by simple interactions between contagious disturbance processes and vegetative dynamics, if the landscape holds a memory of past fires. Ecological processes that are strongly "remembered" by an ecosystem have the potential to become keystone processes that generate ecological structure at specific scales and thus have the potential to entrain other processes and ecological attributes, such as body-size patterns.

Forys and Allen (2002) explore the consequences of species turnover on the body mass pattern and within and across scale distribution of functional groups for the vertebrates of the Everglades ecosystem. They show that despite a large turnover in species composition resulting from species invasions and extinctions, overall body mass patterns do not change substantially; moreover, the richness and distribution of functional groups both within and across scales do not change (although functional group representation does change). Their analysis provides compelling evidence of the robustness and persistence of the patterns detected, suggesting strong self-organization and resilience in the Everglades system despite enormous perturbations.

Allen and Saunders (2002) extend the earlier findings of Allen and others (1999) that first suggested that the discontinuities in animal body mass distributions represent scale breaks. They examine the phenomenon of nomadism in birds in an Australian Mediterranean-climate ecosystem and find that nomadic birds also cluster about scale breaks (that is, they occur at the edge of body mass aggregations). The clustering of these phenomena at predictable scale breaks suggests that variability in resource distribution or availability is greatest at these states. Location at scale breaks affords species great opportunity, but also a potential for crisis. Complex behaviors such as nomadism may evolve most efficiently and commonly at scale breaks, where there is the greatest potential reward, albeit with the highest potential cost.

Bessey (2002) extends the discovery of discontinuities and departures from scaling laws to city-size distributions. He suggests that the landscape of social structures categorized as cities is scale dependent and that inferences about city-size distribution may be misleading if made at inappropriate scales.
City systems reflect humans' adaptation to their environment. Bessey's analysis suggests that there are persistent deviations from scaling laws in citysize distributions analyzed at the appropriate scale and that these deviations reflect city function and evolution.

Cross-scale structure, the partitioning of diversity within and across scales, the importance of scale breaks, and the phenomena associated with scale breaks are fruitful avenues of investigation in the analysis of ecological, economic, and social systems. If discontinuous distributions reflect underlying structure at different scales, the analysis of changes in these distributions will be a powerful tool to assay changes in landscape structure and the processes responsible for maintaining them. It may provide a strong link between the often disparate fields of ecology and economics, and a powerful synthetic tool that can be used to analyze complex systems, such as ecological-economic-social systems, and to offer insight into their generation and their resilience.

\section{ACKNOWLEDGMENTS}

For enabling the research and encouraging the discourse responsible for the papers in this feature, we gratefully acknowledge the support of the MacArthur Foundation, the McDonnell Foundation, the Santa Fe Institute, the National Institute for Ecological Analysis and Synthesis, and the Resilience Alliance. The South Carolina Cooperative Fish and Wildlife Research Unit is jointly supported by a cooperative agreement among the USGS/BRD, the South Carolina Department of Natural Resources, Clemson University, and the Wildlife Management Institute.

\section{REFERENCES}

Allen CR, Saunders DA. 2002. Variability between scales: predictors of nomadism in birds of an Australian Mediterraneanclimate ecosystem. Ecosystems.

Allen CR, Forys EA, Holling CS. 1999. Body mass patterns predict invasions and extinctions in transforming landscapes. Ecosystems 2:114-21.

Bessey KM. 2002. Structure and dynamics in an urban landscape: toward a multiscaled view. Ecosystems.

Brown JH. 1995. Macroecology. Chicago: University of Chicago Press.

Burrough PA. 1981. Fractal dimensions of landscapes and other environmental data. Nature 294:240-2.

Carpenter SR, Leavitt PR. 1991. Temporal variation in palcolimnological record arising from a trophic cascade. Ecology 72 : 277-85.

Crawley MJ, Harral JE. 2001. Scale dependence in plant biodiversity. Science 291:864-8.

Forys EA, Allen CR. 2002. Functional group change within and across scales following invasions and extinctions in the Everglades ecosystem. Ecosystems. 
Havlicek T, Carpenter SR. 2001. Pelagic size distributions in lakes: are they discontinuous? Limno Oceanogr 46:1021-33.

Holling CS. 1992. Cross-scale morphology, geometry, and dynamics of ecosystems. Ecol Monog 62:447-502.

Holling CS, Allen CR. 2002. Adaptive inference for distinguishing credible from incredible patterns in nature. Ecosystems $5: 319-28$

Krummel JR, Gardner RH, Sugihara G, O'Neill RV, Coleman PR. 1987. Landscape patterns in a disturbed environment. Oikos 48:321-4

Lambert WD, Holling CS. 1998. Causes of ecosystem transformation at the end of the Pleistocene: evidence from mammal body mass distributions. Ecosystems 1:157-75.

Levin SA. 1992. The problem of pattern and scale in ecology. Ecology 73:1943-67.

Manly BFJ. 1996. Are there clumps in body size distributions. Ecology 77:81-6.

Milne BT, Johnston K, Forman RTT. 1989. Scale dependent proximity of wildlife habitat in a spatially-neutral Bayesian model. Landscape Ecol 2:101-10.

Milne BT, Turner MG, Wiens JA, Johnson AR. 1992. Interactions between the fractal geometry of landscapes and allometric herbivory. Theoret Pop Biol 41:337-53.

Morse DR, Stork NE, Lawton JH. 1988. Species number, species abundance and body length relationship of arboreal beetles in Bornean lowland rainforest trees. Ecol Entomol 13:25-37.

O'Neill RV, Turner SJ, Cullinam VI, Coffin DP, Cook T, Conley W, Brunt J, Thomas JM, Conley MR, Gosz J. 1991. Multiple landscape scales: an intersite comparison. Landscape Ecol 5:137-44.

Peterson GD, Allen CR, Holling CS. 1998. Ecological resilience, biodiversity and scale. Ecosystems 1:6-18.

Peterson GD. 2002. Contagious disturbance, ecological memory, and the emergence of ecological pattern. Ecosystems.

Raffaelli D, Hall S, Emes C, Manly B. 2000. Constraints on body size distributions: an experimental approach using a smallscale system. Oecologia 122:389-98.

Restrepo C, Renjifo LM, Marples P. 1997. Frugivorous birds in fragmented neotropical montane forests: landscape pattern and body mass distribution. In: Laurance WF, Bierregaard RO, editors. Tropical forest remnants: ecology, management and conservation of fragmented communities. Chicago: University of Chicago Press, p 171-89.

Shorrocks B, Marsters J, Ward I, Evernett PJ. 1991. The fractal dimension of lichens and the distribution of arthropod body lengths. Funct Ecol 5:457-60.

Siemann E, Brown JH. 1999. Gaps in mammalian body size distributions reexamined. Ecology 80:2788-92.

West GB, Brown JH, Enquist BJ. 1999. The fourth dimension of life: fractal geometry and allometric scaling of organisms. Science 284:1677-9.

West GB, Brown JH, Enquist BJ. 1997. A general model for the origin of allometric scaling laws in biology. Science 276:122-6.

Zipf GK. 1949. Human behavior and the principle of least effort. Boston: Addison-Wesley. 